\title{
Arbor
}

\section{El cielo único europeo, implicaciones para la defensa}

\section{Enrique Pina Díaz}

Arbor CLXXI, 674 (Febrero 2002), 301-326 pp.

Su autor nos presenta un tema de gran actualidad y que posiblemente deberá ser tratado durante la Presidencia española de la Unión (primer semestre de 2002), a fin de conseguir que el llamado "Cielo Único Europeo» sea una realidad en diciembre de 2004.

El contenido del artículo es interesante desde el punto de vista profesional militar para poder vislumbrar los problemas con que se va a enfrentar en el futuro el Ejército del Aire, así como para el público en general, pues, en forma amena, se exponen las medidas y formas de llevarlas a cabo si se quiere agilizar y flexibilizar el transporte aéreo en Europa, sin que ello repercuta de forma negativa sobre las necesidades militares.

\section{Introducción}

La industria aeronáutica está inmersa en una evolución dinámica, consecuencia de los continuos cambios legislativos, socioeconómicos y tecnológicos que diariamente la sociedad demanda. Así, factores como la liberalización del transporte aéreo, la búsqueda de la eficiencia en la gestión del tránsito aéreo, la eficaz utilización de los recursos del sistema aeroportuario o la mejora de la calidad del servicio al cliente son factores que han llevado a las compañías aéreas a modificar sus modos de operación y por tanto a propiciar que el transporte aéreo comercial haya experimentado en la última década un elevado crecimiento en Europa que, según las estimaciones previstas, esta tendencia no sólo se va a 
mantener sino que se espera un progresivo aumento en los próximos años.

Esta creciente necesidad, positiva en tantos aspectos, ha puesto en evidencia la limitación de los sistemas de navegación aéreos de que disponen los distintos países europeos, su deficiente compatibilidad e interoperabilidad así como su limitada capacidad de infraestructura aeroportuaria. Esta grave limitación, desde la óptica de los receptores de este servicio público, se ha reflejado en un creciente aumento de las demoras en la utilización del transporte aéreo, lo cual provoca elevados costes económicos, grandes insatisfacciones y la percepción de una deficiente calidad del servicio recibido.

Así, la tendencia actual está orientada a disponer de nuevos procesos de gestión, que puedan proporcionar la necesaria calidad en la prestación de los servicios, así como garantizar el nivel de seguridad aérea requerida, tal y como han señalado organizaciones internacionales, como la Organización Internacional de Aviación Civil (OACI), la Comisión Europea o la Organización Europea para la Seguridad en la Navegación Aérea (Eurocontrol).

Por otra parte la sociedad europea está inmersa en la construcción de un sistema político de integración, que proporcione la deseada estabilidad, libertad, desarrollo y bienestar social y exige a sus representantes y gobernantes actuaciones en la creación de un Estado Europeo de seguridad, justicia y libertad, donde adquieren gran relevancia aspectos derivados de la Seguridad y Defensa nacionales y colectivos, los cuales igualmente están sujetos a una dinámica evolución, consecuencia de los compromisos internacionales adquiridos y de los continuos cambios legislativos y socioeconómicos.

Este aparente conflicto de intereses, derivado de la necesidad de utilización de un único y, en algunos casos, preciado recurso natural: el espacio aéreo, constituye uno de los aspectos más importantes a resolver, a fin de que todos los usuarios del mismo puedan satisfacer sus necesidades, a la vez que atender a los requerimientos de sus máximos responsables políticos, de acuerdo con las demandas de la sociedad de la que forman parte.

\section{La liberalización del transporte aéreo europeo}

Tras la supresión de toda intervención y control gubernamentales sobre la aviación civil, llevada a cabo por la administración norteamericana a finales de los años setenta, con la finalidad de adoptar medidas li- 
El cielo único europeo, implicaciones para la defensa

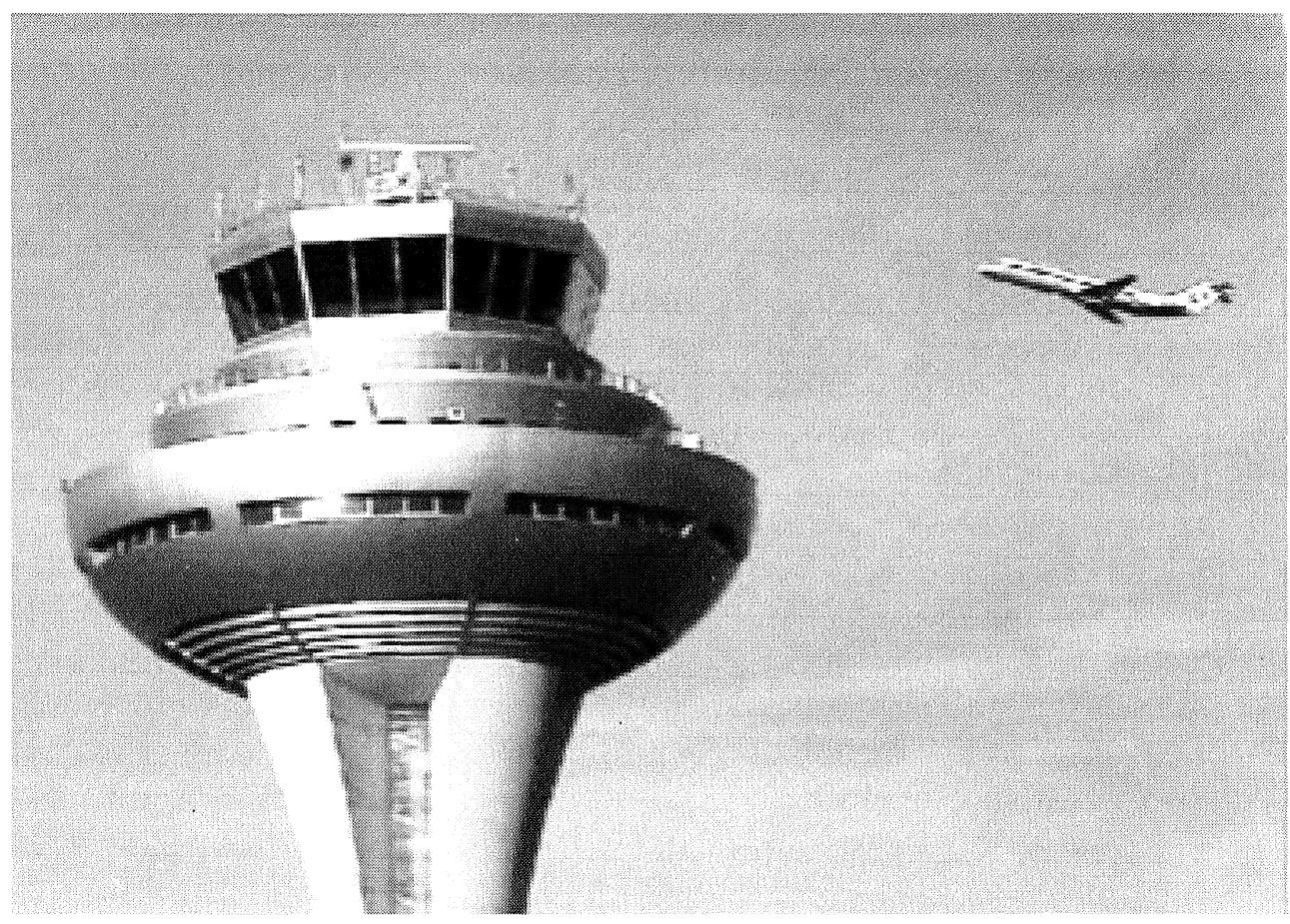

beralizadoras del transporte aéreo, la Comunidad Económica Europea, al inicio de la década de los ochenta, presentó a la Organización Internacional del Transporte Aéreo (IATA) unas propuestas que, con el objetivo de llegar a una política europea para el transporte aéreo, se inclinaban por una liberalización de las tarifas y la introducción de una mayor competencia entre compañías europeas para obtener un mejor servicio público.

Inicialmente, la citada Organización no apoyó el proyecto europeo y así lo expuso en un informe propio, elaborado a los seis años del inicio de la experiencia liberalizadora norteamericana. En el mismo reconoce, que esa iniciativa tuvo resultados positivos y negativos, los cuales, realizando un gran ejercicio de síntesis, se pueden resumir en las siguientes conclusiones:

- Mejora de las estructuras de rutas, pero sin un aumento de la eficacia en su gestión.

- Desarrollo de compañías regionales y de tercer nivel.

- Reducción de tarifas en las rutas de alta densidad de tráfico, pero aumento en las de baja densidad.

- Distorsiones entre precios y costes, los cuales precipitaron que algunas compañías se encontraran en dificultades financieras. 
Por tanto, se produjo un exceso de capacidad, aplicación de tarifas incoherentes y consecución de un rendimiento financiero insuficiente. No obstante, el dinamismo, la potencia y las características del mercado norteamericano permitieron esa total liberalización sin ninguna intervención gubernamental; lo cual puede que no sea directamente aplicable a otras latitudes.

Estas conclusiones reflejaban realmente lo percibido por los distintos medios de comunicación de la época, que en algunas de sus secciones escribían titulares como este: «Caos en el Cielo. El tráfico aéreo en EE.UU es un desastre desde su liberalización». (EL PAIS, domingo 15 de noviembre de 1987) ${ }^{1}$.

Sin embargo, en marzo de 1984 se inició el proceso liberalizador en Europa con la publicación por parte de la Comisión de las Comunidades Europeas del denominado «Memorando número 2», donde se señalaba la estrategia, a largo plazo, de una política del transporte aéreo común para Europa, con dos objetivos fundamentales: flexibilidad y competitividad. En 1987 este proceso recibió un gran impulso con la aprobación de los ministros de transporte de un paquete legislativo que suponía importantes avances en el establecimiento de reglas comunes, predominio de los principios de libre competencia y disminución de la función interventora de los gobiernos en el establecimiento de tarifas; posteriormente, tras sucesivas reuniones ministeriales europeas, hasta la aprobación de la fase final de liberalización -abril de 1997- se ha ido avanzando en este aspecto, que se ha plasmado, entre otros, en un progresivo aumento del transporte aéreo europeo y la puesta en evidencia de la limitación de los sistemas de navegación aéreos que disponen los distintos países europeos, su deficiente compatibilidad e interoperabilidad así como su limitada capacidad de infraestructura aeroportuaria.

\section{Intervención de Organismos Internacionales, relacionados con el transporte aéreo europeo}

La reacción de los Organismos implicados no se hizo esperar y en mayo de 1996, la Unión Europea elaboró un documento, denominado: «libro blanco de la UE sobre ATM», con el objetivo de analizar la gestión del tránsito aéreo en Europa y presentar los puntos de vista de la Comisión Europea.

En el mismo se analizaba la problemática del transporte aéreo europeo y sus deficiencias, se definía una solución y se planteaban una serie de opciones, a fin de optimizar el sistema. 
Las iniciativas comunitarias, hasta esa fecha, no fueron suficientes y, por tanto, el problema continua pendiente de solución. Por ello, a finales del año 2000, la Comisaria de Transporte y Energía de la Unión Europea, Sra. De Palacio, ha presentado un informe de la Comisión Europea al Parlamento y Consejo Europeos, en cuya realización han participado representantes civiles y militares ${ }^{2}$-el denominado Grupo de Alto Nivel-, donde se expone la problemática actual del transporte aéreo y propone una serie de objetivos y líneas de acción para la creación de un espacio aéreo único europeo, gestionado de forma global y centralizada y donde se enfatiza la necesidad de proporcionar un servicio de calidad, a fin de garantizar la seguridad aérea requerida en todos los aspectos relacionados con la aviación.

El citado informe propone la necesidad de acometer significantes reformas en la actual organización de la gestión del tránsito aéreo (ATM) europeo en todos los aspectos, a saber: reguladores, estructurales, institucionales, operativos, técnicos y sociales.

Del estudio del mismo, que más adelante se abordará, se pueden sacar muchas conclusiones y analizar las implicaciones que puede acarrear a la aviación militar en general, pero quizás tenga interés destacar dos aspectos importantes:

- Los intereses económicos y comerciales, en tiempo de paz, puede que tengan mayor peso específico que los intereses nacionales de la Defensa.

- La seguridad aérea debe estar permanentemente garantizada, independientemente de la creciente demanda de utilización y gestión del espacio aéreo.

\section{La política de seguridad y defensa española}

Una de las líneas básicas de la política de Seguridad y Defensa, promulgadas por el actual gobierno y contempladas en la Directiva de Defensa Nacional 1/2000, se refiere explícitamente a los ámbitos de la Seguridad y Defensa como complemento a la acción exterior de España, contribuyendo al mantenimiento de la paz, la seguridad y la estabilidad internacionales y haciendo valer la presencia española en las Organizaciones internacionales relacionadas con esta materia, tales como la Organización de las Naciones Unidas, la Alianza Atlántica o la Unión Europea.

El dinamismo político, social y económico alcanzado por España en el actual y globalizador contexto internacional ha creado la necesidad de establecer, por parte del Gobierno y liderado por el Ministerio de Asuntos 
Exteriores, un plan estratégico para su política exterior en el que se coordinen las sinergias de los Ministerios afectados y se conjuguen los aspectos, no solo políticos, sino económicos, culturales, tecnológicos y militares, de modo que se integren y optimicen los instrumentos de la acción exterior de que dispone el Estado y la sociedad española ${ }^{3}$.

En el mencionado plan se establecen las líneas maestras elaboradas por ese Ministerio donde, entre otras, especifica el gran interés de este Gobierno por promover y participar en el desarrollo de una política de integración europea. Dado que una política exterior ambiciosa y coherente

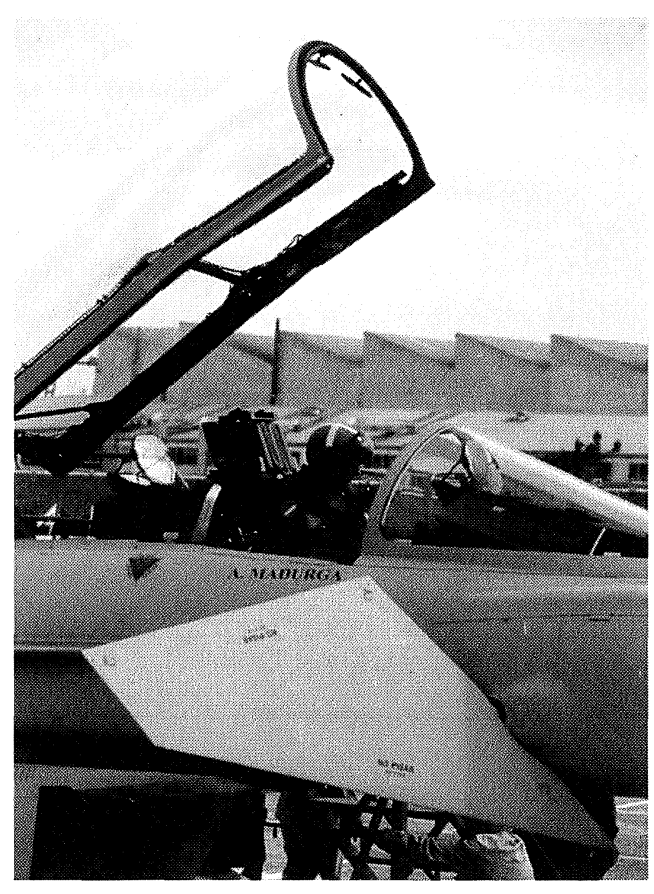
precisa de unas líneas de actuación claras en materia de Seguridad y Defensa, España, en su actuación internacional, ha priorizado e impulsado la Política Europea Común de Seguridad y Defensa (PESC) ${ }^{4}-\mathrm{el}$ denominado segundo pilar de la Unión-y ha intensificado su participación en los foros que se ocupan de la seguridad internacional. Así, desde 1988 viene participando en gran número de operaciones humanitarias y de mantenimiento de la paz y, en enero de 1999, nos incorporamos a la estructura militar integrada de la Alianza Atlántica (OTAN).

\section{El cielo único europeo. Informe del Grupo de Alto Nivel}

Por mandato de la Comisión Europea, el anteriormente mencionado Grupo de Alto Nivel elaboró un informe sobre el establecimiento de un cielo único europeo donde se evalúa la situación actual de la gestión del tránsito aéreo en Europa (ATM), las deficiencias a las que está sometido el sistema, las principales necesidades del transporte aéreo y las necesarias reformas a introducir, especificadas en orientaciones y en grandes líneas de acción con la finalidad de presentar un plan de actuación y una serie de propuestas legislativas, al Parlamento y Consejo europeos, pre- 


\section{El cielo único europeo, implicaciones para la defensa}

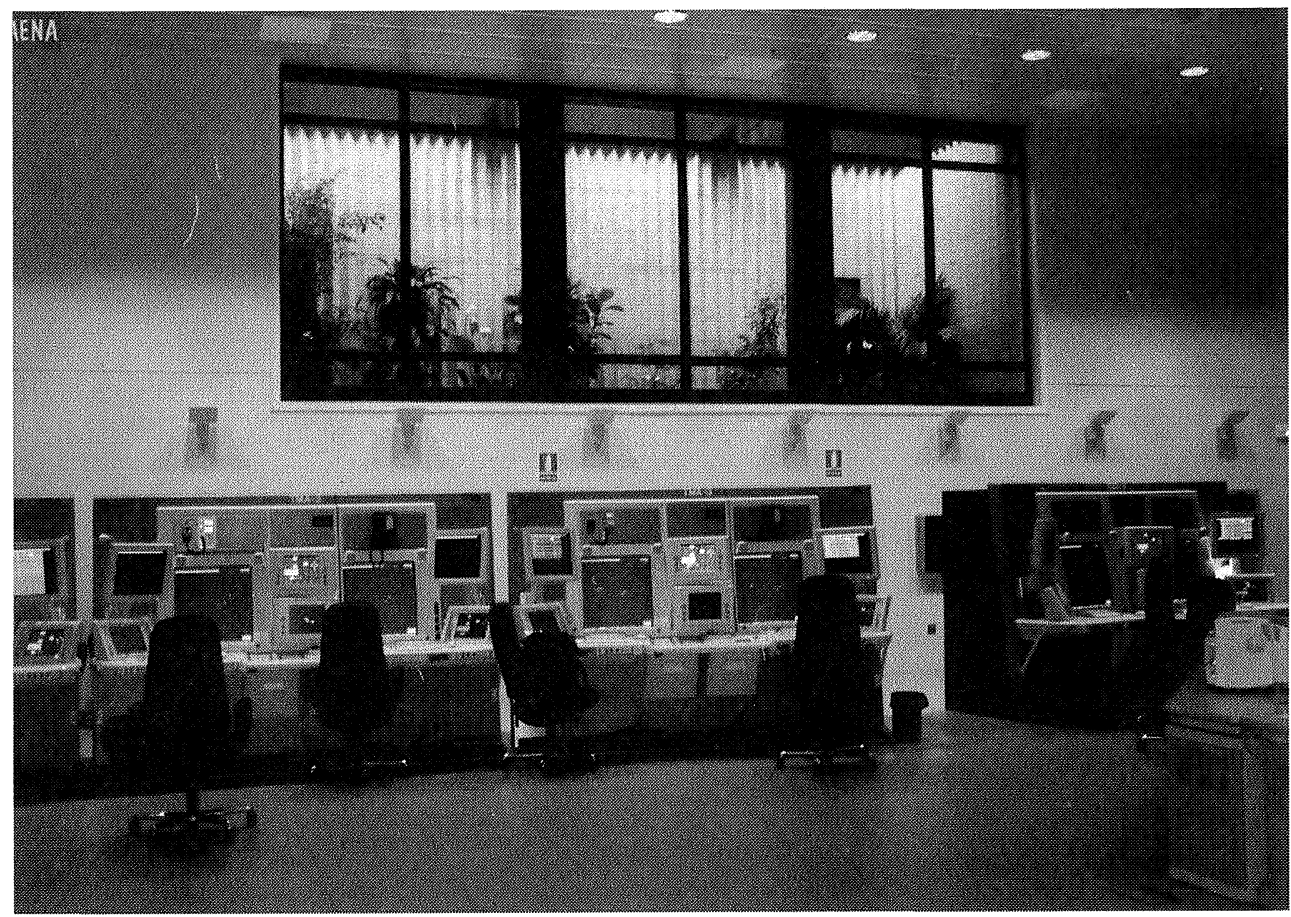

visiblemente durante la Presidencia española de la Unión Europea, prevista para el primer semestre de 2002, donde se propone el 31 de diciembre de 2004, como fecha de implantación.

\subsection{La gestión del transito aéreo en la actualidad}

El transporte aéreo en Europa ha venido creciendo de manera ininterrumpida en la última década a un ritmo de entre un 5 y un $7 \%$ anual. Los datos que ha proporcionado Eurocontrol en su resumen ejecutivo anual fija el citado incremento en torno a un 4,8\%, respecto al año 2000 (figura 1), esperándose un número de movimientos aéreos en torno a los 7 millones para el año 2002. Este crecimiento es previsible que se mantenga en el futuro, lo que significa que el tránsito se duplique cada 12 años aproximadamente (figura 2), sin embargo las iniciativas nacionales introducidas, de manera individual y quizá tardías, de gestión de tránsito aéreo (ATM) no han sido capaces de asumir esta creciente demanda. Ello ha originado la consiguiente saturación del sistema y el aumento de las demoras en el tránsito que sobrevuela Europa, a pesar del objetivo propuesto de no superar los 3,5 minutos de media para la gestión de 
afluencia del tránsito en ruta; las causas de las mismas pueden identificarse en la figura 3.

Es preciso reconocer que las demoras no afectan solamente a las finanzas de las compañías aéreas, ni a los pasajeros que utilizan sus servicios, los cuales sufren largas esperas en los aeropuertos y ven truncados sus planes de viaje, sino que afectan directamente a la economía europea y minan la credibilidad de iniciativas políticas comunitarias relacionadas, tanto con el transporte aéreo ${ }^{5}$ como con la Seguridad y Defensa, la credibilidad de las Organizaciones y el trabajo permanente de infinidad de profesionales en búsqueda de soluciones a este problema común ${ }^{6}$.

Las distintas Organizaciones especializadas, al igual que refleja el informe final del Grupo de Alto Nivel, reconocen que la responsabilidad de las demoras en Europa es compartida entre los proveedores de servicios ATS, las líneas aéreas, los aeropuertos y el uso temporal del espacio aéreo para fines militares.

¿Qué defíciencias es posible identificar en la actual gestión ATM Europea?

El mencionado informe elaborado por la Comisión Europea sobre el cielo único identifica fundamentalmente los siguientes problemas:

- La Organización del espacio aéreo en los distintos Estados miembros presenta grandes diferencias que dificultan su utilización y reducen la efectividad del transporte aéreo.

- El sistema ATM europeo está compuesto por una multiplicidad de centros de control, criterios de sectorización, clasificación de espacio aéreo y estructuración de rutas ATS concebidos para satisfacer las necesidades nacionales, pero en numerosos casos incompatibles entre Estados, lo cual dificulta enormemente la organización del control y flujo de tránsito aéreo y facilita la aparición de innumerables cuellos de botella que se traducen en demoras.

- A pesar de que en muchos Estados existe una integrada y eficaz coordinación civil-militar que permite un adecuado uso racional y flexible del espacio aéreo, esto no es posible en la gran mayoría restante, por lo cual determinadas zonas de espacio aéreo de uso militar no son aprovechables por la circulación aérea general (CAG) e incluso por diferentes usuarios de la Defensa.

- No existe un acuerdo en la industria de las diferentes naciones que faciliten sistemas interoperables, lo cual genera costes suplementarios, presenta graves ineficiencias, no facilita políticas de inno- 
El cielo único europeo, implicaciones para la defensa

vación y desarrollo tecnológico y no permite la necesaria cooperación industrial y normativa.

- En el área de recursos humanos, existe un gran problema de déficit de controladores que origina sobrecargas de trabajo y disminución de las capacidades de control. La situación actual de controladores se refleja en la figura 4 , donde se estima una falta de entre 800 y 1600 controladores de un total de 15000 en toda la Unión. El problema se agravará, de acuerdo con la tendencia demográfica, cuando se produzca el pase a la reserva de un tercio de los existentes, desde ahora hasta 2010. Además los diferentes Estados exigen una formación práctica en el puesto de trabajo, lo cual no facilita la movilidad y por tanto una posible solución al problema.

¿Qué propone el mencionado informe, en lo referente a posibles reformas del actual sistema ATM?

Los principales aspectos del proceso de reforma se derivan de las anteriormente señaladas deficiencias. Las acciones que se proponen son las siguientes:

- reforzar los mecanismos de optimización del funcionamiento de la ATM europeo en su conjunto;

- establecer un espacio aéreo europeo como un único elemento continuo, gestionado en aras de la eficiencia global del sistema;

- garantizar un acceso suficiente al espacio aéreo con fines civiles y militares;

- asegurar el desarrollo de un enfoque coherente del control del tránsito aéreo (ATC) en toda Europa;

- establecer normas de alto nivel a escala europea con miras a la seguridad y el buen funcionamiento del sistema;

- establecer organismos reguladores sólidos e independientes;

- desarrollar un proceso que garantice la aplicación, respaldado por una fuerza legal efectiva;

- respetar las necesidades de Seguridad y Defensa nacionales para el uso del espacio aéreo;

- asegurar la coherencia en el marco institucional;

- cumplir las exigencias básicas del Tratado de la Unión Europea.

\subsection{Objetivo estratégico general y grandes líneas de acción}

El objetivo estratégico general marcado por la Comisaria de Transportes y Energía, Sra. De Palacio, podría definirse como «alcanzar una organización integrada, global y centralizada de la gestión del tránsito 
aéreo en Europa, de acuerdo con las necesidades de todos los usuarios del espacio aéreo y acorde con la política exterior de Seguridad y Defensa común de la Unión Europea, a fin de concebir un cielo único europeo».

Una vez que los miembros del Consejo Europeo den luz verde al citado proyecto, la Comisión Europea presentará un Plan general de actuación, donde se contemplen las necesarias propuestas legislativas, el calendario propuesto de reformas y su correspondiente proceso de implantación.

En un principio, de acuerdo con el citado informe, las principales líneas de acción propuestas son:

\subsubsection{Creación de un marco institucional}

El proceso de creación de un Cielo Único exigirá una normativa completa que habrá de abarcar todas las áreas susceptibles de regulación, como son la seguridad, los aspectos económicos de provisión de servicios, el diseño y uso del espacio aéreo, la cooperación civil-militar y los aspectos técnicos y operacionales. Debe, además, ser efectiva y garantizar el respeto a las reglas por parte de los Estados miembros, de los proveedores de servicios $\mathrm{y}$, por supuesto, de los usuarios.

La competencia sobre las actividades mencionadas pretende

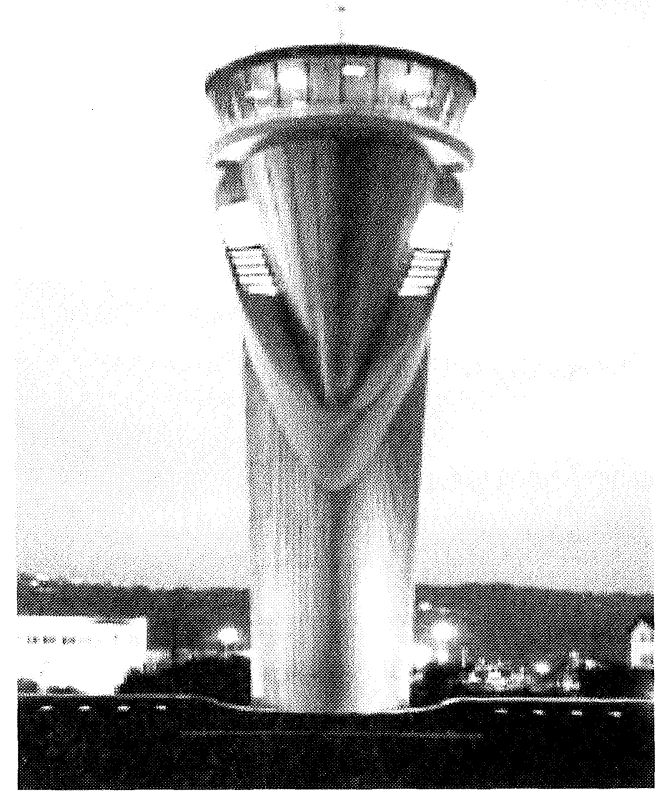
ser asumida por la Unión Europea -es de significar que por el momento no la tiene en el área de Defensa-, y se propone el marco institucional que ofrece la Unión para establecer el necesario proceso regulador, ya que la normativa comunitaria permitirá el control político por parte de los Estados miembros y hará posible la aplicación de los instrumentos legales a la gestión del tránsito aéreo. Igualmente, la futura implementación de una Política Europea de Seguridad Común (PESC) podría facilitar la cooperación entre las Fuerzas Armadas de los distintos países para lograr una mejor utili- 
zación del espacio aéreo europeo. Además, La jurisdicción del Tribunal de Justicia de la Comunidad garantiza la aplicación directa de las decisiones adoptadas y asegurará, por lo tanto, su efectiva implementación en todos los Estados miembros.

\subsubsection{Elaboración de una reglamentación eficiente}

Un sistema de gestión de tránsito aéreo seguro, eficiente y económicamente rentable necesitará disponer, entre otros, de una reglamentación eficiente que abarque todos los aspectos de la ATM, establecer mecanismos de supervisión y de cumplimiento. Debería alcanzar aspectos relacionados con la seguridad, el diseño y funcionamiento del sistema, el diseño del espacio aéreo, así como los aspectos económicos, garantizando y fortaleciendo, en cualquier caso, la seguridad en la aviación.

El órgano regulador será el responsable de definir las normas y garantizar su cumplimiento, las cuales afectarán a todos los grupos de interés: proveedores de servicios, usuarios del espacio aéreo, aeropuertos e industria. Este nuevo Organismo debe ser independiente, centralizado y con la suficiente autonomía que le permita desarrollar un nuevo marco regulador a nivel europeo, determinar los requerimientos esenciales comunes en el área de espacio aéreo y con capacidad de imponer las decisiones adoptadas a todos los organismos y colectivos implicados a modo de legislación comunitaria. La implantación de tales decisiones en países europeos no comunitarios se prevé mediante acuerdos bilaterales o multilaterales.

Tal y como ya se analizó en el libro blanco de la Unión Europea sobre ATM del año 1996, se mantiene la conclusión de que las funciones reguladoras deben mantenerse separadas y perfectamente diferenciadas de las operativas, responsabilidad de cada uno de los Estados miembros.

\subsubsection{Seguridad en la navegación aérea.}

La seguridad en el transporte aéreo es considerada fundamental y todos los profesionales relacionados con el ATM deben concederle un carácter prioritario en el desarrollo de sus funciones. El incremento del tránsito aéreo, la progresiva automatización y la creciente integración tecnológica entre los sistemas de a bordo y de tierra van a significar, sin duda, nuevos desafíos para los responsables de la seguridad.

Mientras la gestión del tránsito aéreo tiene como función primaria el garantizar la seguridad, la falta de directrices claras y estándares definidos y cuantificables en este área deja esta responsabilidad en manos de 
los controladores, sin que se les haya proporcionado directrices claras al respecto. Esta carencia dificulta, asimismo, una visión objetiva de la seguridad de funcionamiento global del sistema. En consecuencia, se considera absolutamente prioritario y urgente el fortalecimiento de las actuales estructuras y procesos en esta materia para asegurar y mejorar en lo posible los actuales niveles de seguridad.

La Comisión tiene previsto, en el año 2005, establecer un organismo regulador en materia de Seguridad ATM que controlará los grandes cambios que habrán de ser introducidos en los próximos años, a la vez que será responsable de establecer los necesarios objetivos y estándares en este campo. Dicho organismo será creado en el marco de la actual Agencia Europea para la Seguridad de la Aviación (EASA) por decisión del Consejo Europeo.

No obstante, mientras no exista este organismo será necesario garantizar que la seguridad en el tráfico aéreo se siga gestionando de manera eficaz, por lo que, en este intervalo, la Comisión para la Regulación de la Seguridad (SRC) de EUROCONTROL debería continuar desarrollando su normativa, actualmente único documento vinculante a todos los Estados miembros, los denominados requerimientos reguladores de la seguridad ATM y su implementación en las estructuras estatales. La finalidad de los mencionados requerimientos, conocidos como ESARR,s (Requerimientos Europeos para la Regulación de la Seguridad), es garantizar la utilización, por parte de los proveedores de servicios ATM, de sistemas de gestión de seguridad eficientes.

\subsubsection{Diseño y gestión del espacio aéreo}

El modelo que propone la Comisión está basado en que el espacio aéreo es un recurso único y común, que habrá de ser diseñado y gestionado como tal, sin tener en cuenta las fronteras nacionales, especialmente en lo que se refiere al espacio aéreo superior. La creciente demanda de utilización necesita el establecimiento de una regulación sólida y eficiente, tanto en cuanto a su arquitectura como en lo relativo a su diseño y gestión que en la actualidad no permiten hacer frente a la demanda prevista.

El principal requisito para la reforma, en esta materia, es aceptar la necesidad de un planeamiento común del espacio aéreo europeo que permita una estructura común y armonizada, una distribución y utilización de ese medio, de acuerdo con unos principios y procedimientos comunes, así como un diseño de rutas y sectorización, acorde con las necesidades reales.

Además de este espacio aéreo pan-europeo debería mantenerse una estructura nacional, responsable de establecer requerimientos específi- 
cos a ese nivel, pero compatible con un planeamiento y diseño supra-nacional. En este aspecto se considera fundamental una estrecha e intensa cooperación civil-militar.

Todos los usuarios -aviación comerciạl, aviación general y aviación militar- necesitan libre acceso al espacio aéreo, por lo que deben racionalizarse al máximo las zonas permanentemente reservadas. El uso coordinado del espacio aéreo por los usuarios civiles y militares debería establecerse mediante procedimientos bien definidos; dichos procedimientos habrán de tener en cuenta las particularidades de la utilización para fines militares.

Para resolver estạ cuestión, podrían contemplarse las siguientes mejoras:

- El concepto de uso flexible de espacio aéreo (FUA) debe ser implementado de manera uniforme y eficiente en todos los Estados, con la finalidad de observar las bondades del modelo, a la vez que debería establecerse una auténtica coordinación e integración civilmilitar, en lo relacionado con todas las actividades ATM7 ${ }^{7}$.

- Será preciso impulsar la integración entre la planificación de aeropuertos, compañías aéreas y la gestión del flujo de tránsito aéreo para permitir una toma de decisiones en cooperación, mejorando el intercambio de información en tiempo real, a fin de potenciar su efectividad.

- En caso de congestión o crisis, se considera imprescindible reforzar la función de la Unidad Central de Gestión de Afluencia (CFMU), en estos momentos responsabilidad de Eurocontrol, para integrar la planificación estratégica, pretáctica y táctica de los flujos de tránsito, con la finalidad de establecer prioridades en la asignación de franjas horarias.

\subsubsection{Sistemas ATM Europeos}

Aunque en los últimos años se han realizado importantes progresos para conseguir una operación uniforme del sistema ATM europeo, la mejoría alcanzada es, todavía insuficiente, ya que aún perdura un deficiente nivel de integración entre los diferentes sistemas nacionales. Por lo tanto, ante la necesidad común de implementar nuevos conceptos, técnicas y procedimientos para hacer frente al incremento del tránsito, deberían desarrollarse sistemas, que permitieran su interoperabilidad.

En definitiva, se considera necesario optimizar los recursos europeos y buscar soluciones a necesidades operativas comunes, lo cual facilitaría 


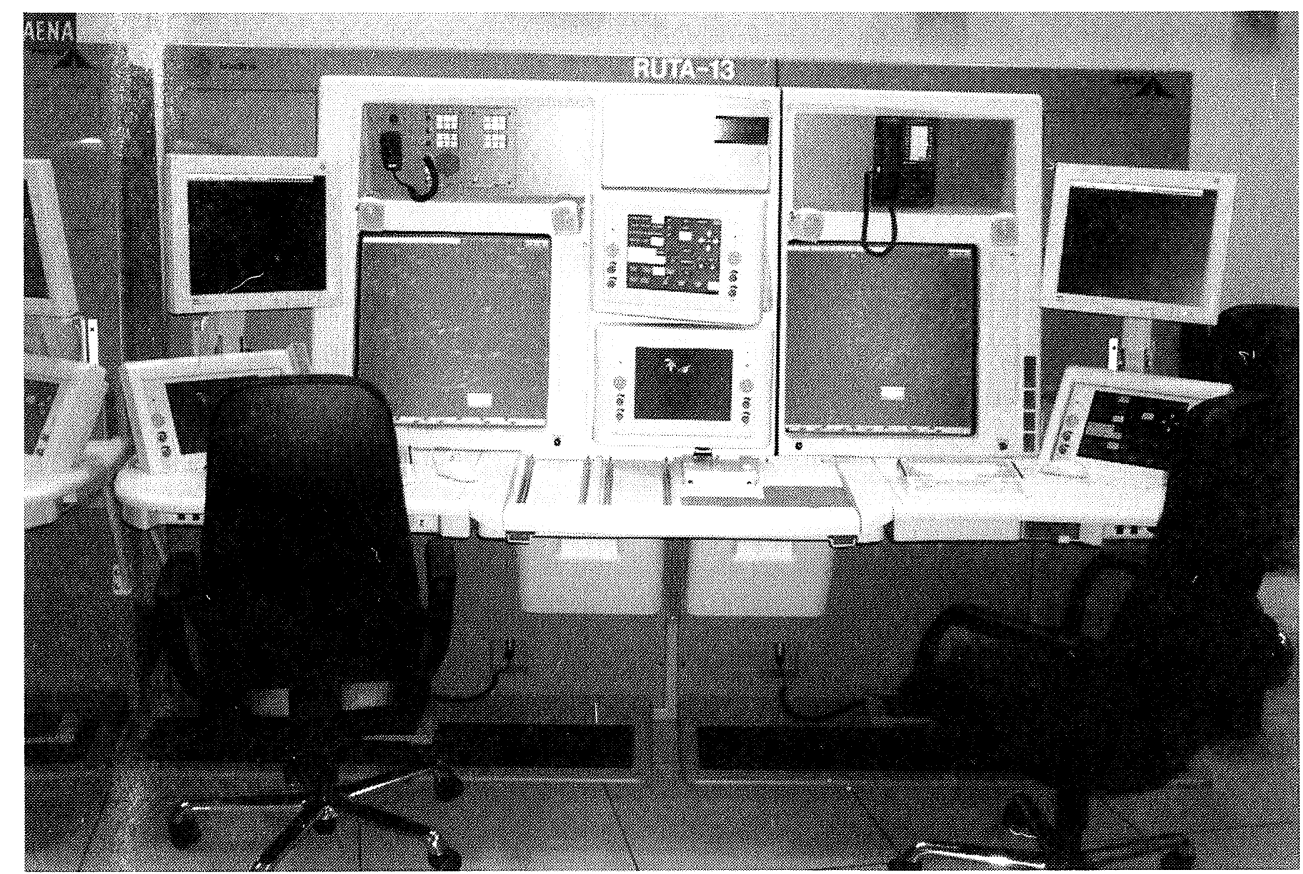

la consecución del objetivo de minimizar las demoras. Ello podría alcanzarse mediante:

- Una mayor cooperación entre los responsables de la industria ATM, que permita un mejor aprovechamiento de los recursos y minimice la duplicidad de recursos.

- Unos requerimientos operativos, aceptados a nivel europeo, que permitan a la industria una previsión de necesidades de producción, con el consiguiente ahorro que ello supondría.

- Un organismo europeo, responsable de la validación de nuevos sistemas, de acuerdo con unos requisitos operativos previamente definidos.

\subsubsection{Las operaciones militares}

Los datos que ha proporcionado Eurocontrol en su resumen ejecutivo anual muestran que, en el conjunto del tránsito gestionado por el sistema ATM europeo, las operaciones militares suponen menos de un $5 \%$. Además no hay que perder de vista que el tránsito civil ha aumentado de forma continua en los últimos 10 años y sin embargo se han reducido considerablemente las operaciones militares en el espacio aéreo europeo.

Lo que sí es cierto, y quizá difícil de entender, es que ese reducido porcentaje de operaciones militares no está proporcionado con el, aparente- 
El cielo único europeo, implicaciones para la defensa

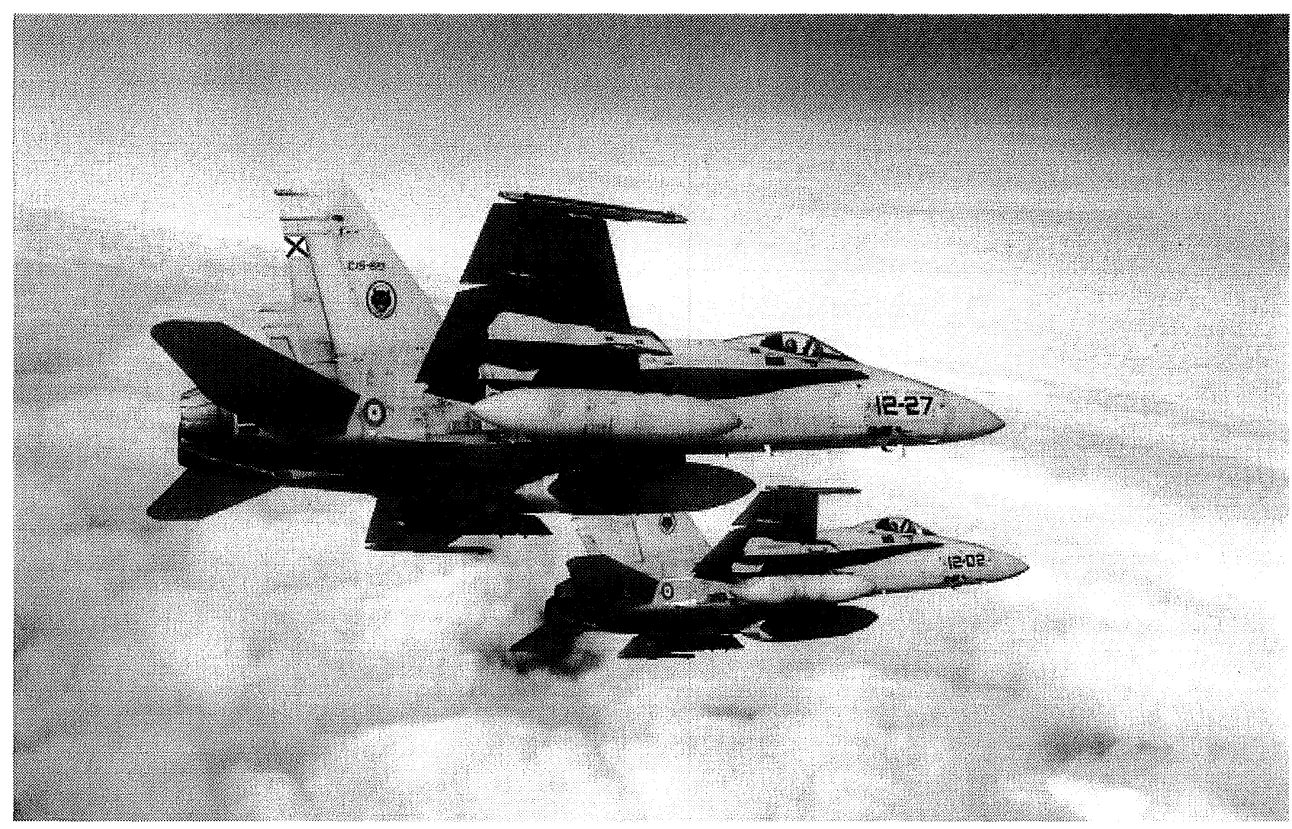

mente, excesivo volumen de espacio aéreo reservado para estos fines. La fría observación de una carta aeronáutica de Europa, donde están representadas todas las zonas prohibidas, restringidas, peligrosas o susceptibles de ser temporalmente segregadas pudiera resultar, sin duda, alarmante para un profano en la materia.

Las operaciones militares necesitan un elevado volumen de espacio aéreo durante un tiempo muy reducido, es por ello que una adecuada coordinación civil-militar y una adecuada implantación del concepto Uso Flexible del Espacio Aéreo (FUA), donde se tengan en cuenta las necesidades de los usuarios, civiles y militares, puede minimizar el impacto de las operaciones militares sobre la fluidez y seguridad del tránsito aéreo civil, como se demuestra en la realidad.

\section{Los intereses de defensa en el establecimiento de un Cielo Único Europeo}

El establecimiento de un Cielo Único Europeo puede afectar a los intereses de la Defensa Nacional, a pesar de lo establecido en la normati$\mathrm{va}^{8}$ relacionada con esta materia, actualmente en vigor. Así, el citado proyecto europeo debería:

- Garantizar el mantenimiento del control del espacio aéreo de soberanía nacional, por Organismos de la Defensa. 
- Permitir el acceso de las aeronaves militares al espacio aéreo, sin restricciones.

- Analizar objetivamente las repercusiones del uso del espacio aéreo por aeronaves militares.

Respecto al primer apartado, la legislación vigente atribuye al Ejército del Aire la responsabilidad del control del espacio aéreo de soberanía nacional ${ }^{9}$. Esta responsabilidad debe ser ejercida, tanto en tiempo de paz, como de crisis o guerra. En paz, se materializa con la vigilancia del espacio aéreo, el conocimiento de la situación aérea y la intervención de aeronaves. En situaciones de crisis, el control del espacio aéreo asegura la libertad de acción requerida para llevar a cabo las operaciones aéreas en defensa del territorio.

La estructuración del espacio aéreo con independencia de las fronteras nacionales, tal y como contempla el informe sobre el cielo único europeo, incluye la posibilidad de prestación de servicios de tránsito aéreo sobre una nación por dependencias ATS situadas en otra. Esta delegación de servicios ATS en ese espacio aéreo puede afectar directamente al conocimiento de la situación aérea, a la coordinación entre la circulación aérea general y operativa y, en general, a la libertad de acción de las aeronaves militares; en definitiva, a la soberanía. Además, no hay que olvidar que la situación geoestratégica de España requiere un efectivo control del espacio aéreo.

Respecto al segundo apartado, un espacio aéreo diseñado por un organismo supranacional, sin un estudio profundo, podría condicionar la utilización de las áreas de entrenamiento a los horarios de menor afluencia de tráfico civil, establecer posibles restricciones a la segregación de espacio aéreo para ejercicios, limitar el acceso al espacio aéreo de las aeronaves militares no equipadas según los estándares civiles o determinar la reubicación de las actuales áreas de entrenamiento, en función de los flujos de tránsito civiles, lo cual podría incidir negativamente en el cumplimiento de la misión que las Unidades, terrestres, navales y aéreas tienen asignada.

Respecto al tercer apartado, existe una equivocada percepción generalizada de que las actividades militares y las áreas reservadas para dichas actividades son, además de un grave inconveniente para un uso óptimo del espacio aéreo, una de las principales causas de las demoras en Europa. Esta visión necesita ser corregida si se desea obtener una mejora en ỉa gestión del tránsito aéreo.

Los datos proporcionados por la Unidad Central de Gestión de Afluencia (CFMU), a la hora de determinar las causas de las demoras, indican que sólo un $4 \%$ de ellas pudieran ser atribuidas, de una u otra manera, a actividades militares. Este mínimo porcentaje no significa, no 


\section{El cielo único europeo, implicaciones para la defensa}

obstante, que la activación de ciertas áreas en determinados períodos de tiempo no pueda influir negativamente en la capacidad del sistema ATM en algunas áreas conflictivas.

Aunque diversos informes de la Comisión de Seguimiento (PRC) de EUROCONTROL especifican que durante los fines de semana, cuando las actividades militares son prácticamente inexistentes, la demora sufrida por el tráfico civil es, en la mayoría de los casos, superior al de los días laborables cuando hay actividades militares. No obstante, es justo reconocer que todavía existen áreas donde una mejor coordinación civil-militar podría tener un efecto positivo en la capacidad total del sistema, por lo que es preciso seguir investigando sobre nuevas formas de colaboración.

\subsection{Características de la aviación militar}

En general, las operaciones militares exigen un perfil de vuelo y un comportamiento sensiblemente diferente al de la aviación civil. Dichas operaciones, sólo posibles en áreas segregadas, pueden variar desde ejercicios de una o varias aeronaves que implican una gran maniobrabilidad,

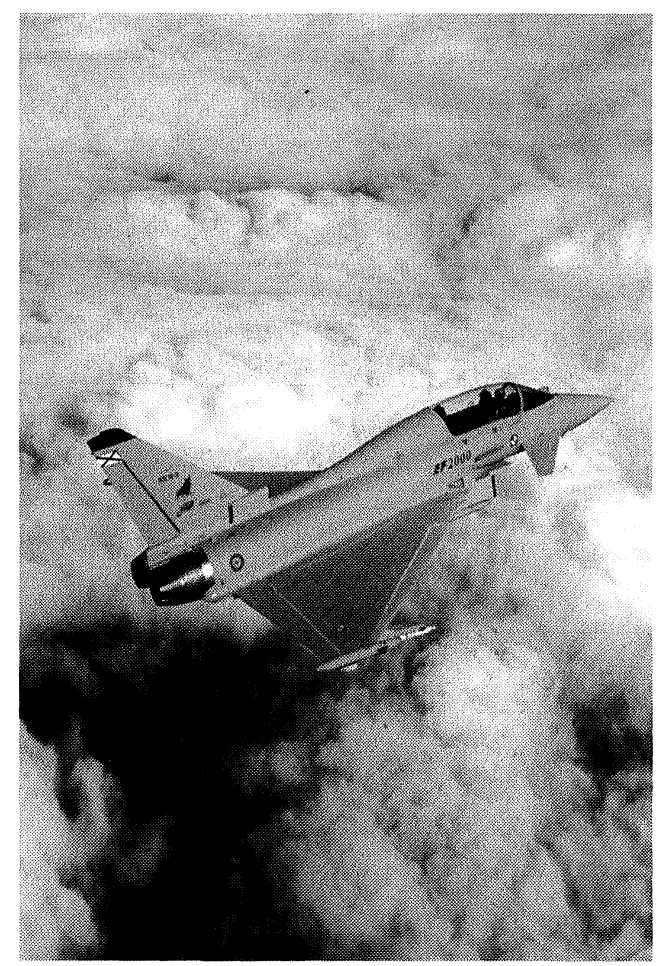

hasta escenarios complejos que incluyen grandes formaciones con un perfil de vuelo variable. No obstante, un número considerable de vuelos militares utilizan principalmente la estructura de rutas y procedimientos de la Aviación General (CAG), de acuerdo con las reglas establecidas por la OACI. Se pretende, por ello, que las aeronaves militares se adapten, en la medida de lo posible, a los mismos requerimientos que la aviación civil y sean equipadas con los nuevos sistemas de navegación, comunicaciones y vigilancia, en la mayoría de los casos innecesarios para cumplir su misión militar.

Sin embargo, las aeronaves militares no pueden adaptarse estrictamente a los requerimientos exigidos para la aviación civil. Ello es 
debido a las limitaciones físicas que no permiten más aviónica o debido a que el espacio disponible, tal como ocurre en los aviones de combate, no permite acomodar los equipos necesarios para ejecutar la misión militar.

Además, las limitaciones presupuestarias y la imposibilidad de recuperar unas inversiones hechas sin un propósito militar definido, tienen un efecto negativo a la hora de decidir el cumplimiento de todos los requisitos civiles. Ello hace necesario la aplicación de políticas de exención y el desarrollo de reglas y procedimientos especiales para asegurar el libre acceso al espacio aéreo de la aviación militar, equipada o no según los estándares civiles.

Las Fuerzas Armadas se esfuerzan, sin duda, en lograr un óptimo aprovechamiento de los escasos recursos disponibles, tanto financieros como de personal y material. Es necesario, en este sentido, extraer el máximo rendimiento de las cada vez más limitadas horas de vuelo asignadas para entrenamiento. Por ello, las fases menos aprovechables del vuelo, como son el tránsito hacia y desde zonas de entrenamiento intentan reducirse al mínimo. La situación ideal sería, no cabe duda, que las áreas de entrenamiento estuvieran situadas en las proximidades de las bases de despliegue de las Unidades.

Como se ha mencionado, la gran mayoría de los desarrollos en materia de Comunicaciones, Navegación y Vigilancia, así como en el área de Gestión del Tránsito Aéreo (CNS/ATM), promovidos en el seno de EUROCONTROL, no están basados en requerimientos militares. No obstante, y en la medida de lo posible, la aviación militar intentará cumplir con los mismos requisitos exigidos a la aviación civil en materia de equipamiento, colaborando de esta manera a un aumento de capacidad en beneficio del tráfico civil. Sin embargo, la citada imposibilidad de recuperar los costes asociados sugiere una nueva posibilidad que consiste en establecer algún mecanismo de compensación o incentivo que resuelva esta problemática.

\subsection{Necesidad de espacio aéreo por razones de defensa}

El espacio aéreo es utilizado por las fuerzas terrestres, navales y aéreas para cumplir las misiones asignadas por el gobierno de cada país, que incluyen no sólo la defensa militar del territorio y la protección de la soberanía, sino también las misiones en el marco de organizaciones internacionales en las que el Estado se encuentra comprometido, lo cual exige un entrenamiento adecuado.

En la última década, Europa ha visto reducido significativamente el número global de aviones militares, sin que se prevean modificaciones importantes en el futuro. En la actualidad, la mayor actividad se produce en 
operaciones llevadas a cabo en coalición en el marco de compromisos internacionales con la participación de diferentes tipos de aviones, equipos y tácticas. Los ejercicios conjuntos son, en consecuencia, esenciales para una ejecución segura y con éxito de operaciones de mantenimiento o, en su caso, imposición de la paz. Además de lo anterior, existen otras necesidades de acceso al espacio aéreo para diversos tipos de misiones relacionadas con la seguridad y defensa nacional que deben, asimismo, ser respetadas.

La realidad indica, por lo tanto, que las Fuerzas Armadas tienen en la actualidad un abanico de misiones más amplio que antes, lo que, unido a la aparición de aviones de combate más sofisticados, nuevo armamento y la utilización creciente de Vehículos Aéreos no Tripulados $(\mathrm{UAV}, \mathrm{s})$ exigirá una mayor disponibilidad de espacio aéreo ${ }^{10}$ para entrenamiento y operaciones, aunque se prevé, por el contrario, una reducción en el tiempo total de utilización.

Para satisfacer estas necesidades de entrenamiento de las unidades de tierra, mar y aire, existe en todos los países un número de áreas reservadas a tal fin y preestablecidas en función de ciertos condicionantes, como son la seguridad y los flujos de tráfico civil. Es obvio que determinados vuelos de entrenamiento militares necesitan de un volumen de espacio aéreo segregado, sin embargo, estas áreas son activadas exclusivamente durante el tiempo necesario. Sin duda, una efectiva implementación del concepto FUA en toda Europa será la mejor contribución en aras de aliviar los actuales problemas de congestión del sistema ATM.

\section{Coordinación civil-militar}

Una vez analizadas las crecientes necesidades del transporte aéreo y de la Seguridad y Defensa desde el punto de vista de la utilización de un medio natural común, como es el espacio aéreo, una adecuada coordinación civil-militar constituye la clave para la consecución de los objetivos de todos los usuarios.

El mencionado informe de la Comisión Europea contempla, como no podía ser de otra manera, la integración de las necesidades militares en el establecimiento de un cielo único europeo. Así, destaca que el éxito de esta iniciativa depende de una eficaz cooperación entre el sector civil y el militar, lo cual requiere la participación plena del estamento militar, en plano de igualdad, en el proceso regulador, en la gestión integrada del espacio aéreo. Todo ello debería respetar los requisitos nacionales de Seguridad y Defensa y el establecimiento de un uso flexible y racional del espacio aéreo, basado en procedimientos y reglamentos nacionales comunes y coherentes con la política comunitaria. 
Los diferentes Estados europeos asumen el compromiso de mantener una organización nacional civil-militar al más alto nivel, aunque no así en los niveles más bajos, lo cual se refleja en el resultado operativo final.

Independientemente de la Organización ATM establecida, cada Estado mantiene, por las necesidades de la Seguridad y Defensa nacionales, un Sistema de Vigilancia y Control independiente (puramente militar), siempre coordinado con las dependencias de control (ATC) civiles y/o militares.

No obstante, las diferentes Organizaciones ATM europeas podrían encuadrarse en alguno de los siguientes modelos:

- Una organización civil que gestiona y controla ambos tipos de tránsito, civil y militar.

- Una organización civil-militar, totalmente integrada, que gestiona y controla ambos tipos de tránsito, civil y militar.

- Dos organizaciones, civil y militar, gestionadas de forma separada pero con una adecuada integración, a nivel de gestión y de control operacional, a menudo compartiendo las mismas instalaciones y operando equipos similares.

- Dos organizaciones, civil y militar, gestionadas de forma separada.

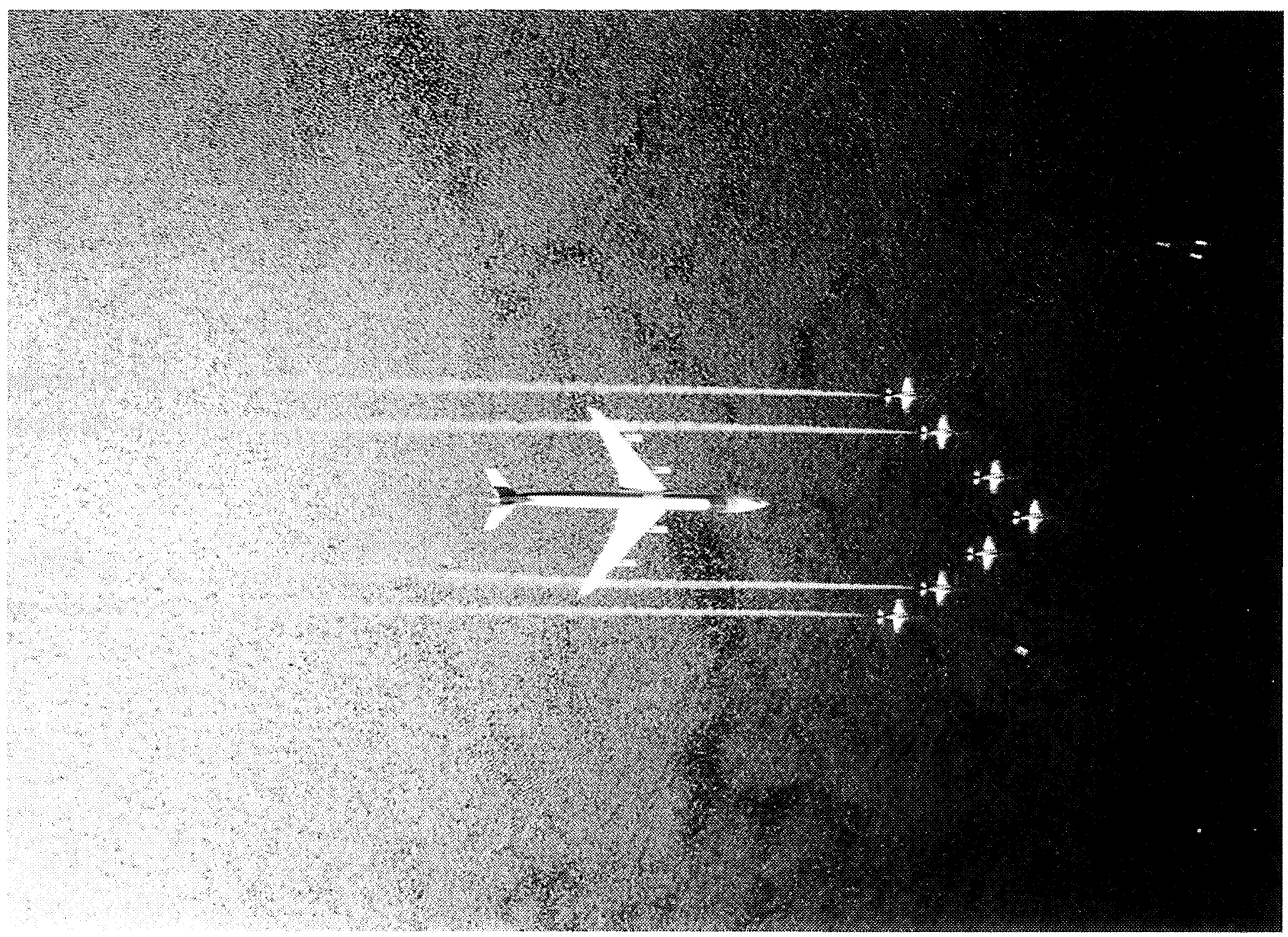




\subsection{La gestión del transito aéreo en España}

En el modelo español participan, por parte del Ministerio de Fomento: Dirección General de Aviación Civil/AENA y por parte del Ministerio de Defensa, el Ejército del Aire/Estado Mayor.

La Coordinación civil-militar se materializa en tres niveles de Gestión del Tránsito Aéreo (ATM):

Nivel 1, Gestión Estratégica: Fijada desde un aspecto regulador, a través de un Organismo interministerial, Defensa-Fomento: CIDETRA y desde un aspecto operativo, Estado Mayor del Aire-Dirección General de Aviación Civil/Aena.

Nivel 2, Gestión Pre-Táctica: Realiza la gestión diaria del espacio aéreo (ASM) y de la afluencia del tránsito aéreo (ATFM), a través la Célula Conjunta, civil-militar, de gestión del espacio aéreo (AMC).

Nivel 3, Gestión Táctica: Consiste en la activación, desactivación o reasignación en tiempo real de espacio aéreo asignado a Nivel 2 , así como la resolución de situaciones específicas o conflictos entre la circulación aérea general (CAG) y la operativa (CAO). Requiere de una coordinación directa y en tiempo real entre los controladores civiles y militares.

Este modelo (ver figura 5) podría garantizar una adecuada coordinación civil-militar, desde el punto de vista conceptual; sin embargo, la realidad ha puesto de manifiesto una serie de carencias, a nivel estratégico y pretáctico, que es preciso analizar e intentar mitigar. Una posible alternativa sería el establecimiento de un modelo similar al contemplado en la figura 6 y en la implantación efectiva de los niveles dos y tres (pretáctico y táctico).

\section{Conclusiones}

En el sector aeronáutico se tiene una equivocada percepción de que las actividades militares y las áreas reservadas para esos efectos son, además de un grave inconveniente para un uso óptimo del espacio aéreo, una de las principales causas de las demoras en Europa. Sin embargo, diversos informes de Organizaciones de reconocido prestigio especifican, que durante los fines de semana, cuando las actividades militares son prácticamente inexistentes, la demora sufrida por el tránsito aéreo civil es, en la mayoría de los casos, superior a la de los días laborables cuando se desarrollan actividades militares.

En una Europa que goce del necesario clima de estabilidad, los intereses de Seguridad y Defensa pueden correr el riesgo de ser progresiva- 


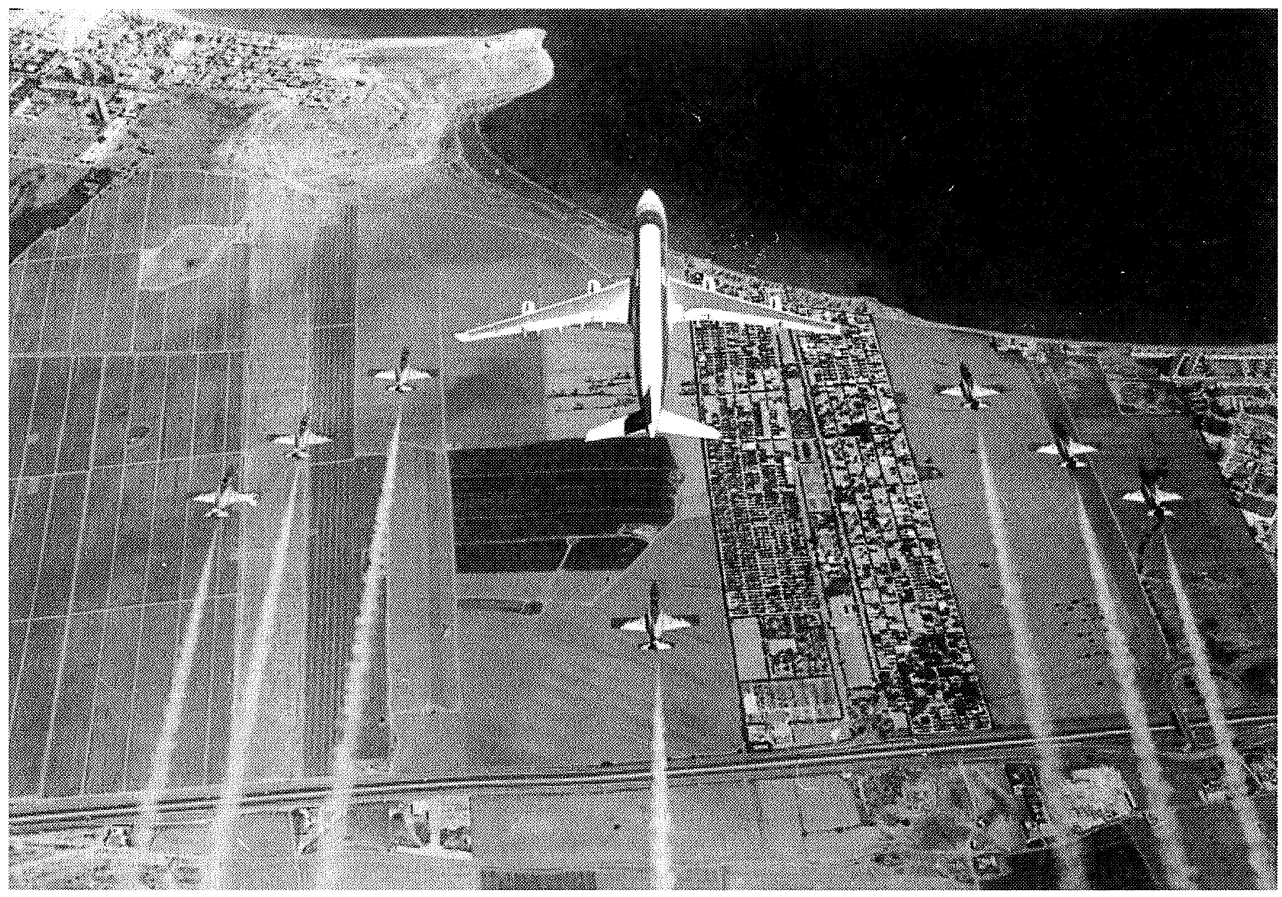

mente relegados a un segundo plano, tal y como aparece reflejado en la futura concepción de la gestión del tránsito aéreo europeo, a pesar de que en ella se contemplen las necesidades militares nacionales y no se cuestionen aspectos relacionados con la soberanía. En dicha orientación se intuye una propuesta de solución a la problemática del sector aeronáutico civil, en clara expansión, donde confluyen grandes intereses económicos y comerciales.

En la mencionada propuesta, la Comisión Europea pretende asumir competencias en el área de Defensa, en base a una Política Exterior y de Seguridad Común, por el momento sin desarrollar. En este sentido, es necesario la creación de un foro civil-militar, a nivel europeo, donde se pudieran exponer las necesidades de la aviación militar y se garantizasen los intereses de Defensa y de Soberanía nacionales. Este foro sería, a nivel supranacional un reflejo del foro nacional existente.

La problemática del transporte aéreo europeo podría minimizarse, mediante el establecimiento de una eficiente coordinación civil-militar europea. Así, en el contexto español, sería preciso revisar la actual organización del tránsito aéreo, de tal manera que los Organismos implicados: Dirección General de Aviación Civil, Aena y el Ejército del Aire, desarrollaran sus cometidos de una manera más integrada y coordina- 


\section{El cielo único europeo, implicaciones para la defensa}

da para afrontar sus necesidades aeronáuticas nacionales e internacionales.

\section{Notas}

$1 \ll \mathrm{El}$ resultado liberalizador ha consistido en un aumento espectacular del $25 \%$ en el tráfico aéreo en los últimos tres años. La economía también se ha beneficiado y los consumidores y las empresas se ahorraron ese año 1000 millones de dólares gracias a las tarifas más baratas. Pero todo tiene un límite. Hace ya un par de años comenzaron a quebrar líneas aéreas».

${ }^{2}$ En el caso español, por parte del Ministerio de Fomento participaron representantes de la Dirección General de Aviación Civil y de la Dirección de Navegación Aérea de Aena y por el Ministerio de Defensa, representantes del Estado Mayor del Aire y del Mando Aéreo de Combate (MACOM).

${ }^{3}$ Una respuesta semejante, integrada y coordinada en sus aspectos políticos, económicos, tecnológicos, culturales y militares ha sido puesta en acción por el gobierno de EE.UU., ante el lamentable atentado terrorista ocurrido el pasado 11 de septiembre en ese país.

${ }_{4}$ España ha contribuido activamente a que se tomaran las decisiones pertinentes en los Consejos Europeos de Colonia, Helsinki, Lisboa, Feira y Niza de dotar de unas capacidades militares comunes específicamente europeas y establecer instituciones en el marco de la Unión Europea dedicadas a gestionar esta nueva dimensión de nuestra política común, tal como el nombramiento de «mister PESC», la creación de un Comité Político y de Seguridad y un Comité Militar.

$5 \mathrm{El}$ pasado 12 de septiembre de 2001, la Comisión Europea ha presentado un libro blanco sobre «la política de transporte europeo para el 2010: tiempo para decidir».

${ }^{6}$ Lamentablemente, acontecimientos como los ocurridos el pasado 11 de septiembre en EE.UU., quizás sirvan como catalizador para impulsar importantes iniciativas comunitarias, de tal manera que se orienten las sinergias económicas, de Seguridad y Defensa y jurídico- policiales previstas en el Tratado de la Unión.

${ }_{7}$ Se considera que la credibilidad y el éxito de la reforma del sistema ATM en Europa dependerá de la participación de la parte militar en la definición y en la implementación del marco regulador. En este sentido, el establecimiento de una Política Europea de Seguridad Común que defina y coordine las necesidades europeas de Defensa, en las que se incluirían las correspondientes al uso del espacio aéreo, permitiría la consecución del objetivo propuesto, lo que hasta la fecha no se ha conseguido en la mayoría de los países.

${ }^{8}$ Ley Orgánica 6/80, modificada por la Ley Orgánica 1/84, de Criterios Básicos de la Defensa Nacional y la Organización Militar. Real Decreto Ley 12/78, sobre delimitación de competencias en materia de aviación entre los Ministerios de Defensa y Fomento. Real Decreto 2161/93, por el que se establecen las condiciones para la asunción, por el Ejército del Aire del control de la circulación aérea general en situaciones de emergencia o crisis. Real Decreto 1489/94, por el que se aprueba el Reglamento de la Circulación Aérea Operativa.

${ }^{9}$ Espacio aéreo situado sobre el territorio nacional y sus aguas jurisdiccionales (hasta las 12 millas de la costa).

10 Se prevé, en definitiva, la creación de áreas de entrenamiento más grandes pero en un número que se pretende que sea más reducido, y cuya ubicación no coincida con los principales flujos de tráfico civil. 


\section{Anexo figuras}

\section{FIGURA 1}

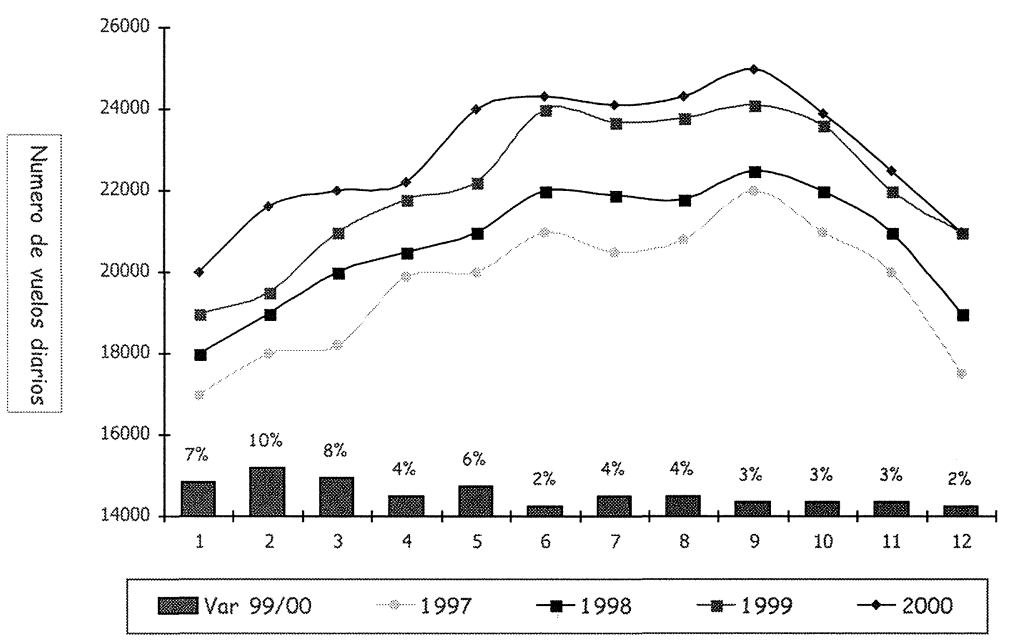

FiguRA 2

NO ANUAL DE VUELOS TFR (en miles)
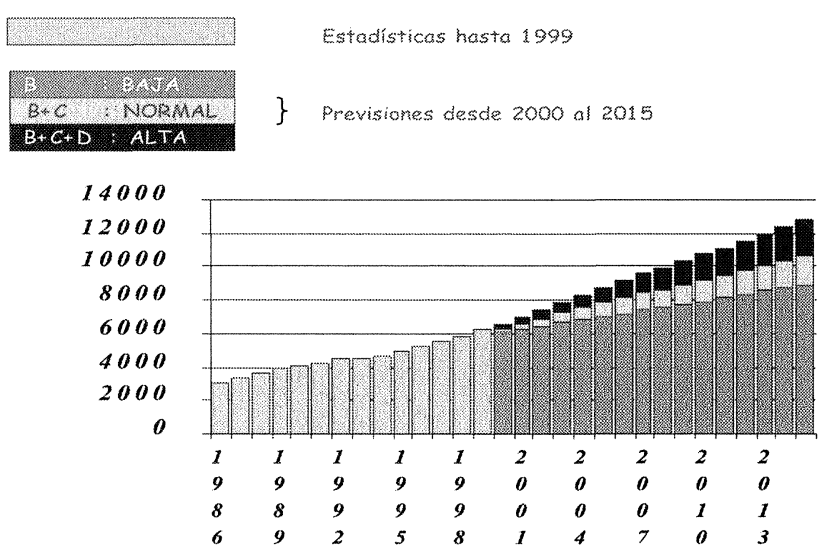


\section{El cielo único europeo, implicaciones para la defensa}

\section{FiguRA 3}

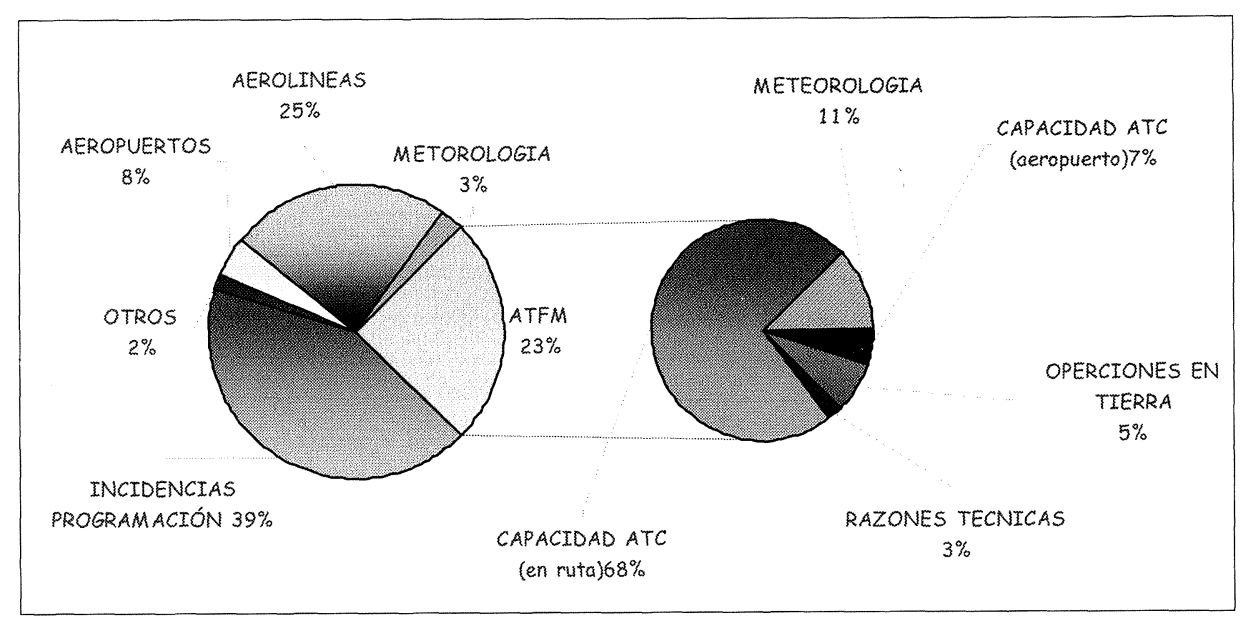

Figura 4

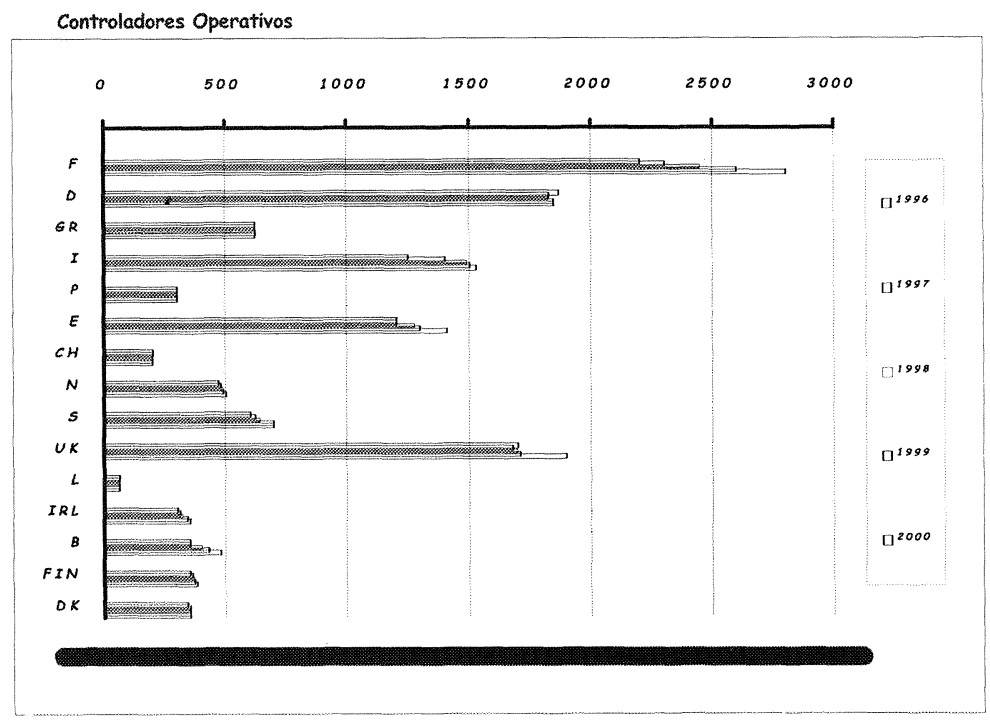

Fuente: Estimación de los Estados Miembros 


\section{Enrique Pina Díaz}

\section{FigurA 5}

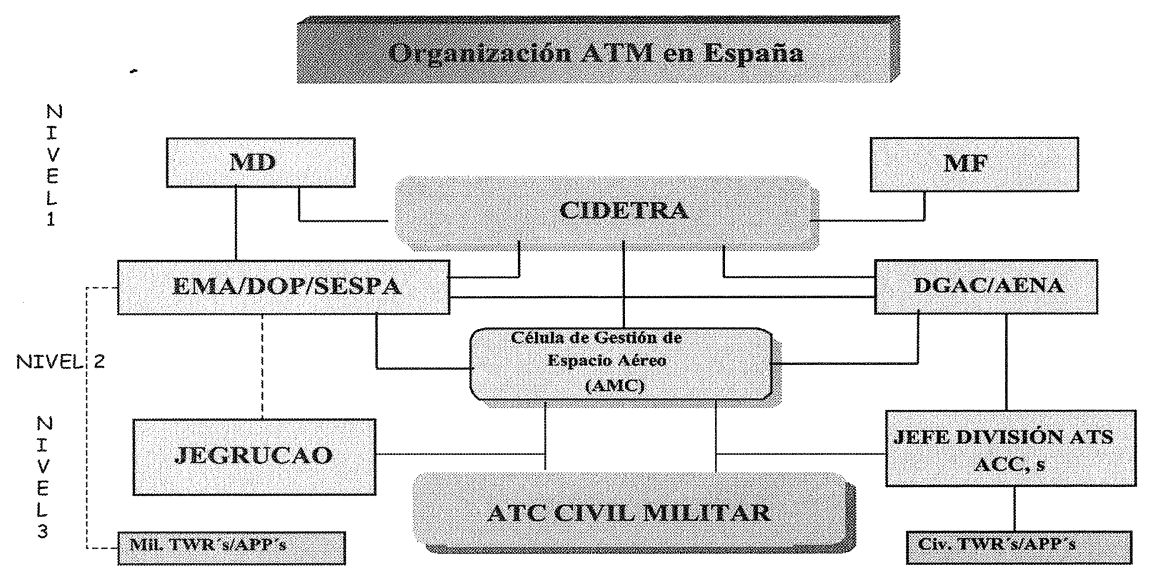

Figura 6

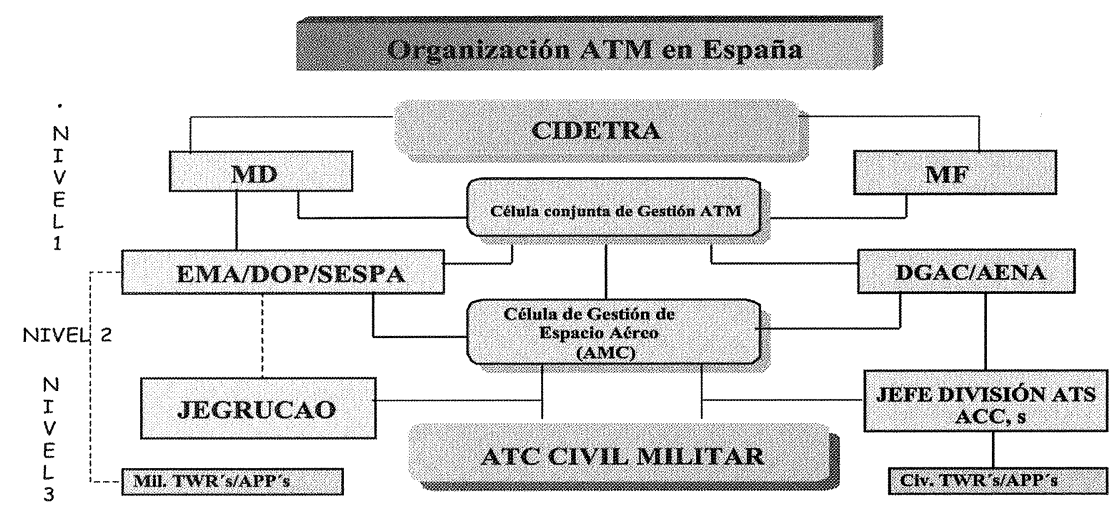

